\title{
Examining and quantifying the drivers behind alterations and extensions to commercial buildings in a central business district
}

\begin{abstract}
The drive to undertake building adaptation has increased momentum, the primary reason being adaptation can be less expensive than new build and conventionally result in faster project delivery times (Ball 2002). The issue of sustainable development is another clear driver for adaptation (Douglas 2006) and collectively buildings contribute around half of all greenhouse gas emissions. At the same time governments seek effective and efficient ways of reducing the contribution of cities to climate change and building adaptation appears to offer a practical means of reducing building related emissions. One example is the '1200 building program' which aims to increase adaptation rates with a target of 1200 city centre office adaptations by 2020 as part of the strategy to achieve carbon neutrality. Through a longitudinal examination of building adaptations it is possible to identify the nature and extent of typical levels of adaptation, as well as determining the inter-relationship between different types of adaptation and building attributes. Using Melbourne city centre for a case study this research analysed 5,290 building adaptation events between 1998 and 2008 . The findings promote the adaptive reuse of buildings in specific circumstances and are directly applicable for increasing sustainability in the built environment. The case study used existing buildings in a global city to ensure relevance to urban centres where existing commercial buildings can become part of the solution to mitigate climate change.
\end{abstract}

\section{Keywords}


Adaptive, Australia, commercial property, refurbishment, sustainability.

\section{Introduction}

With the drive to reduce the contribution of cities to climate change and global warming, building adaptation appears to offer a direct means of reducing building related greenhouse gas emissions. An example of a policy driver is the ' 1200 building program' developed by the City of Melbourne which aims to adapt 1200 central business district (CBD) properties with sustainability measures before 2020 as part of their initiative to become carbon neutral ((Lorenz et al. 2008). Both the rate and scope of building adaptation will have to increase to meet this target and the strategy, therefore: what can stakeholders in the built environment learn from the patterns of previous adaptation practices to inform the future? Through an examination of building adaptations in cities centres it is possible to identify the nature and extent of typical levels of building adaptation, which will then highlight the relationship between adaptation levels and building attributes. The research question this paper addresses is: What is the nature of the relationships between (a) building adaptation events in the CBD classified as 'alterations and extensions' and (b) building attributes?

The emphasis was placed on the nature of the relationships between previously identified (a) building adaptation events classed as 'alterations and extensions' in the Melbourne CBD between 1998 and 2008 and (b) building adaptation attributes identified in the literature as being important decision-making factors. Previous studies have attempted to 
conduct large scale detailed studies but have been limited due to barriers such as data restrictions and reliability issues. This study overcomes these limitations with every building adaptation event which occurred in the Melbourne CBD between 1998 and 2008 examined in detail.

\section{Defining building adaptation}

Building adaptation is defined as: "any work to a building over and above maintenance to change its capacity, function or performance' in other words, 'any intervention to adjust, reuse, or upgrade a building to suit new conditions or requirements"(Douglas 2006). This is a broad definition and enables an analysis of a wide range of building adaptations both within use and across use and also from minor to major works. In the context of this research 'adaptation' refers to changes to buildings and not to the measures used to respond to consequences of climate change.

\section{Factors influencing building adaptation and measurement issues}

Previous studies identified and grouped factors affecting building adaptation under categories of economic, social, environmental, technological, legal and physical where these categories have been clearly defined in previous research (see Wilkinson et al. for a detailed description of factors (2009a, 2009b). The key issue to resolve when evaluating the potential for adapting an existing building has not been the identification of the individual factors influencing adaptation, rather assessing the degree of the importance of different attributes within an adaptation. 
Factors have been identified to assess the potential of vacant office buildings for change of use adaptation to residential (Remøy and van der Voordt 2007). An evaluation checklist was divided into 'location' and 'building' specific attributes and comprised a checklist where higher scoring buildings were deemed less suitable for adaptation than lower scoring stock. Seven location-based factors including 'urban situation' and 'proximity to other facilities' were adopted with eight building-related factors including 'potential for lateral and vertical extension' and 'structural condition' to assess whether a building had low or high potential for change of use adaptation. Remøy and van der Voordt's (2007) work followed on from an earlier study by Geraedts and de Vrij (2004) which developed a 'transformation meter' to assess adaptation potential in Dutch offices. A model was proposed with an initial tool referred to as 'Quick Scan' which identified whether there was an enthusiastic developer, willing seller, the possibility of rezoning for planning if needed and whether a scheme would be economically viable based on approximate costings. The final stage comprised a checklist to identify risks with adaptation and a good range of factors were identified however there was no assessment of whether any factor, such as the physical condition of the building, was more or less important than design attributes such as building width. It should be noted also that these studies focused specifically on change of use adaptation only.

Langston et al (2007) developed the Adaptive Reuse Potential (ARP) Model which used varying types of obsolescence as measures of adaptation criteria. The criteria were physical which measured maintenance policy and performance; economic measuring building location and population, functional which assessed the flexibility of layout to 
accommodate change, technological which measured operational energy, social which measured user demand and finally legal which measured building quality. Six aspects of obsolescence determine the 'useful life' from an equation which states that 'useful life' is discounted physical life, and uses the method of discount, where the discount rate is the sum of the obsolescence factors per annum. Each of the six criteria used in the model were weighted equally and other influencing factors identified by previous studies were not evaluated. Langston et al. (2007) concluded a building with the maximum reduction for each type of obsolescence will have a useful life calculated at about one-third of its physical life. An index that prioritises buildings according to their ARP then expresses this potential as a percentage. The ARP model is relatively easy to use and provides a measurable outcome although it is based on a limited number of factors.

Other limitations with this approach, as Langston et al (2007) stated, are questions about rankings which are influenced by the building's age and the need to include other factors such as the social, economic and environmental advantages of adaptation. Moreover a focus on single factors such as monetary issues leads to biased decision-making, clearly the measurement of adaptation attributes are multiple and complex. This is further compounded as with the drive towards sustainability, social and environmental factors become more important and in some respects less easy to quantify because they are less tangible by nature. Langston et al. (2007) quantified adaptive reuse potential and noted issues with models having narrow focus, high expense and complexity. 
Some earlier studies identified attributes perceived to influence adaptation, see Wilkinson et al.( 2009a, 2009b) for a detailed discussion of the different attributes. The attributes used in this current study are listed in Table 1 with the balance of this paper focused on those attributes found to be important in adaptation. A study of vacant industrial buildings in Stoke on Trent argued the local economy contributed to adaptation (Ball 2002), for example where areas experience economic decline incentives are required to encourage building adaptation. The same study concluded that physical building attributes were deemed important by stakeholders involved in the process such as age, physical condition, heritage value and size (i.e. smaller buildings were more marketable) . These findings complemented an earlier study which concluded building quality and character were determinants of successful adaptation as they provided a sound construction on which to work and delivered buildings which has high appeal to users and purchasers, however the study was limited to a survey of 15 firms in adaptation and provided no major statistical analysis (Ball 1999). A study of Italian education buildings concluded that building accessibility was a critical success factor related to the ease of the construction works, along with building layout and flexibility for a range of differing uses (Fianchini 2007). The study was limited to one university and did not facilitate a more broad examination of the relationships between the adaptation influencing factors.

A landmark study observed a relationship between age and obsolescence in an examination of London offices Barras (1996). The work showed that as buildings age they become more prone to obsolescence which impacts on their capital and rental value. 
The result is that changes are needed in the form of adaptations to defer obsolescence and age is linked with economic viability.

Physical attributes impact on adaptation potential and should be considered in decisionmaking, Gann and Barlow (1996) showed the technical issues in adapting offices were size and height, depth, structure, envelope and cladding type, internal space layout and access, services, acoustic separation and fire safety. Other physical attributes included site (e.g. car parking, orientation, external noise and external access), size (e.g. floor area, height, depth, floor shape, grids, and floor to ceiling height), structure (e.g. penetration for services), envelope (e.g. cladding and thermal issues), services (e.g. to meet new use requirements), acoustic separation (e.g. floors and partitions, flanking transmission) and fire protection (e.g. means of escape, brigade access, detection and alarms, prevention of spread of flames).

Location is clearly an important criterion for adaptation with older buildings occupying prime sites considered ripe for urban regeneration and redevelopment (Ball 1999; 2002). Ellison and Sayce (2007) noted that within the paradigm of sustainability, location can be interpreted in a new way, as accessibility to the building's user group and transport nodes such as rail and bus transport systems which add to the desirability of a property for adaptation. It was possible to some but not all of the attributes identified by previous studies because of the retrospective nature of this research which examined adaptations which occurred in the Melbourne CBD from 1998 to 2008. Table 1 summarises building adaptation attributes identified in previous research and used in this study. 
Table 1. Summary of Attributes Influencing Building Adaptation. - insert here

\section{Degrees and types of adaptation}

There are different attributes which influence building adaptation and also varying levels of adaptation ranging from minor to major. In a study of the London office market all types of building adaptation were classified into four levels (Kincaid 2002). Arup (2008)

developed a similar approach with a five level classification, however Kincaid (2002) and Arup (2008) varied what they included within their respective definitions of adaptation and what is included in minor and major works. Minor works include work such as redecorations and retention of the existing external fabric with minor modifications externally (Kincaid, 2002), whereas Arup (2008) included installation of blinds, revision of the space plan and redecorations in low level works. High change adaptations include replacing external fabric, changing building structure and reconfiguring internal space (Kincaid, 2002). Complete adaptation is where only sub-structure, superstructure and floor structure is retained and substantial alterations occur to the façade (Arup, 2008). In the same model it should be noted that demolition is included and occurs when no suitable cost effective adaptation can be accommodated; the starting point is after the decision has been taken to adapt and the remaining choice is about deciding the optimum level of adaptation. Another layer exists where there are different types of adaptation such as 'within use' and 'across use' or 'change of use' adaptations to consider (Ellison 
\& Sayce, 2007). In Wilkinson et al. (2009b) other issues such as the stakeholder perspectives and potential adaptation outcomes were discussed.

Minor works (i.e. the least work undertaken), alterations works (i.e. including revisions to the space plan, redecorations and retention of the existing external fabric with minor modifications externally), change of use (from one land use to another, office to residential), alterations and extensions (major work including reconfiguring internal space, changes to the structure and fabric, services and decorations), demolition and new build were examined (see summary in Table 2). The focus of this paper is placed on adaptive reuse and accordingly only building adaptation events classified as 'alterations and extensions' (level 4) are examined further. Note for a detailed discussion of alterations adaptations (level 2) see Wilkinson \& Reed (2010)

Table 2. Building adaptation level and title - insert here 


\section{Methodological issues}

Building adaptation and the associated decision-making process is a complex issue with multiple variables to consider. Previous studies (see Remøy and van der Voordt 2007;

Langston et al. 2007) have confirmed the accurate identification of the factors influencing adaptation can be challenging and relatively subjective. To overcome these barriers this research adopted an innovative approach and compiled a comprehensive database with detailed records of all adaptation events. Therefore this study did not rely on individuals personal preferences although it identified and evaluated a large number of building adaptation events.

The challenge is manifold, firstly it is to develop a model which is not narrowly based on a limited number of attributes of which the relative importance in adaptation is unknown, except anecdotally. Secondly, it is to avoid expensive, time consuming and complex tools and thirdly it is to avoid potential bias. This paper deals with the first step in the process which is to identify the attributes which are important in building adaptation from non biased sources.

\section{Research Method}

Previous studies examining the criteria for building adaptation adopted a case study approach based on in-depth analysis of a relatively small sample of buildings (Austin 1988; Barras and Clark 1996; Ohemeng 1996; Blakstad 2001; Heath 2001; Ball 2002; 
Kincaid 2002; Kucik 2004; Arge 2005; Remøy and van der Voordt 2007). From these studies adaptation criteria were identified, however the approach is fundamentally different due to the detailed volume of data and the method used. Firstly adaptation criteria were indentified and formed the fields for the building attribute database.

A building attribute database of commercial buildings in the Melbourne CBD was assembled and populated from sources including the 'Cityscope' database (RPData 2008), 'PRISM' database produced by the State Government of Victoria's Department of Sustainability and Environment (DSE 2008) and through commercial data produced by the Property Council of Australia (PCA 2007; PCA 2008). Building adaptation events were extracted from building permits received by the Building Commission in Victoria with supporting information gathered by visual building surveys. The building attribute database included variables listed in Table 1 which were coded as physical, social, legal, economic and environmental attributes of adaptation. The risk of an unrepresentative sample was avoided through the adoption of a census approach. Every building adaptation event between 1998 and 2008 within the Melbourne CBD is examined and in total 13,222 building adaptation events occurred.

The preliminary task was to define the geographic area for the study which is representative on a global scale; this research sought to investigate activity in a well developed, mature commercial market. The CBD was the initial area laid out in Melbourne in 1834 and has been continuously occupied since. In a similar manner to 
other international cities this area has remained the most mature property market in Victoria with the highest level of demand.

\section{Principal Component Analysis (PCA).}

It is generally accepted that PCA is a reliable, proven method of highlighting dimensions in cross sectional data (Horvath 1994) with the capacity to uncover, disentangle and summarise patterns of correlation within a data set (Heikkila 1992). PCA condenses information contained in a number of original variables into a smaller set of new composite factors with a minimum loss of information (Hair et al. 1995) and was used to reduce the dimensionality of office building attribute data relating to adaptation in the CBD between 1998 and 2008. All building adaptation attributes were examined to identify the degree of variance explained with the objective being to identify the highest level of variance explained by an interpretable group of factors. Initially all variables were entered into the PCA to produce a smaller number of components where factors with Eigenvalues exceeding 1.0 were retained. The factors were rotated using an oblique 'Oblim' rotation method with a final result being a table of identifiable factors which includes the loadings of individual building attributes.

7,393 building adaptation events occurred between 1998 and 2008 in the CBD to commercial buildings for which full address details could be determined. 5,290 were 'alterations and extensions' 0.71 of all adaptation events. Assigning meaning involves interpretation of the pattern of the factor loadings and is somewhat subjective (Hair et al. 
1995). Following an analysis of the loadings across the factors the minimum threshold was 0.5 as recommended by Tabachnick \& Fidell (2001). With the list of each factor containing high loading building attribute variables, the researchers assigned factor names. This analysis examined all events classed as 'alterations and extensions' the most extensive degree of adaptation in the study and coded as level 4 adaptations.

\section{Procedure}

\section{Steps $1 \& 2$}

After the initial extraction using 42 variables, the reduced variables retained for ‘alterations and extensions' adaptation events (level 4) were:

1. Aesthetics

2. Vertical services

3. Parking

4. Street frontage (metres)

5. Historic listing

6. Number of storey's (height)

7. Age in 2010

8. Typical Floor Area

9. GFA

10. Property Council of Australia Building Quality Grade

11. Site boundaries

12. Site access 


\section{Property location}

\section{Step 3}

The first heading under initial Eigenvalues shows the variance explained by each of the thirteen variables (Hinton, Brownlow et al. 2004). Three components explain 0.73 of the original variance. The third section shows the Eigenvalue of each of the three rotated components. Note that as the components are correlated with each other there is some overlap in the variance explained by each factor (Francis 2007). The total amount of variance explained by the three components cannot be obtained by adding the three Eigenvalues. For the rotated solution the factor loadings are given in the table headed Pattern Matrix (table 3) and correlations are given in the table headed Structure Matrix (see table 5). Table 3 shows the three components for this PCA.

Table 3. Total Variance Explained PCA Level 4 adaptation events - insert here

Table 4. Pattern Matrix for Level 4 adaptation events - insert here

\section{Results}

\section{Component One}

The variables number of storey's, Gross Floor Area (GFA), Property Council of Australia Building Quality Grade, site boundaries and typical floor area and site access are highly 
loaded on component 1 (table 4 ). These variables explain 0.44 of the original variance where the component one has six variables, three relating to the physical dimensions and size of the property in terms of floor area and height (i.e. physical attributes). Of the remaining variables, two related to site boundaries being (a) the degree of attachment to neighbouring buildings and site access and (b) the number of access points to the building. It is possible to refer to these attributes as 'physical and size'. The final variable 'Property Council of Australia Building Quality Grade' is strongly and negatively loaded and relates to building quality. With a loading of .427 'parking' is too weak to be included in the final interpretation.

\section{Component Two}

Three variables were loaded very high to high on component two; street frontage, vertical services location and location (table 4 ) and they explained 0.19 of the variance. In this component the variables were influenced by land and design factors. The street frontage or width of the land parcel and the location of the property relate to land attributes. The vertical services are a design attribute that influence the flexibility of the space plan to adapt to different configurations of the floor plate.

Table 5. Summary of Level 4 PCA Component Categories - insert here 


\section{Component Three}

The variables historic listing and age are very strongly and moderately loaded on component three and explained 0.09 of the variance (table 4). Age is negatively loaded. Aesthetics is loaded on component three and relates to building appearance indicating that buildings having a poor appearance, i.e. outdated or worn, are less likely to be adapted. The variables can be collectively described as social. Table 5 summarises the main PCA component categories and the component names ascribed by the interpretation.

\section{Discussion of 'alterations and extensions' adaptations}

'Alterations and extensions' adaptations are those involving the most extensive works. The highest number of events featured in this category, illustrating that owners of Melbourne office buildings were more likely to engage in this type of adaptation than any other from 1998 to 2008, and this level of adaptation indicates high levels of confidence in the market. In other words 'alterations and extensions' adaptations recoup the investment through higher rental yields, increased capital values and lower vacancy rates than if the building was unaltered or adapted to a lesser extent.

\section{Component One - physical and size}

This component contained all the variables in component one for the PCA to 'alterations' adaptations (level 2), see Wilkinson et al. (2010) for a description of the 
PCA for 'alterations' adaptations. There is a strong relationship between variables that are most strongly correlated in level 2 and level 4 adaptations. An additional variable appears for 'alterations and extensions' adaptations; Property Council of Australia Building Quality grade. The results illustrate that with more extensive (and more costly) adaptations the quality of the building (i.e. Property Council of Australia Building Quality Grade) is more important.

Stakeholders take into account the number of storeys and floor area where Povall \& Eley (Markus 1979) and Gann \& Barlow (1996) noted that height was an important physical factor in adaptation. Typical floor area showed a high loading and refers to the amount of floor area per floor typically provided within a building and relates to the physical dimensions of the buildings or size. Kincaid (2002) concluded floor size in London office buildings affected the degree of adaptability in a building where a Dutch study study found an optimum floor size for office adaptations (Arge 2005). The results of this study showed that buildings with large floor plates were more likely to be adapted (0.59) than those with smaller floor plates (0.09), while medium size floor plates accounted for 0.31 of events.

In addition there was an identified relationship between Property Council of Australia Building Quality Grade and building size; with all other variables being equal generally the larger the building and the better the specification in respect of building services and equipment, the higher the Property Council of Australia Building Quality Grade. The grading system classifies premium as the highest and best office grade, followed by A, B, 
$\mathrm{C}$ and D. Some office buildings are not be graded in the system and are classed 'ungraded' The inclusion of Property Council of Australia Building Quality Grade and its high loading is confirmed as Premium, Grade A and B stock has higher rates of adaptation than Grade $\mathrm{C}$ and $\mathrm{D}$ stock. Further examination of the data investigated the type of adaptation by Property Council of Australia Building Quality Grade (table 6).

\section{Table 6. Adaptations by Property Council of Australia Building Quality Grade (all grades)}

As a proportion of all work undertaken, Premium stock had more extensive work undertaken over the timeframe, with 0.84 of premium adaptations being 'alterations and extensions'. No change of use adaptation occurred and the second most likely type of adaptation was alterations ( 0.12$)$ followed by minor work (0.04). Owners of this stock almost always elected to undertake major adaptation work rather than any other type to retain the classification 'Premium'. A similar profile emerged with A Grade stock.

With B grade stock the total amount of work is greater in quantity and some 'change of use' adaptation occurred. Owners of B grade stock are either forced to or perceive a higher return on their investment through changing from one use to another. As with Premium and A Grade stock, the preference is for alterations and extensions thereby owners are instigating more substantial works in order to retain the level of quality within the building or seek to increase to a higher grade. With the $\mathrm{C}$ grade stock there is much 
less work done overall; the profile is more similar to the B grade stock than the Premium or A stock.

Owners of $\mathrm{C}$ grade stock were less inclined to spend or invest on adaptation. $\mathrm{C}$ grade stock has the highest running costs and represents a good opportunity to reduce greenhouse gas emissions through sustainable adaptation either through improvements to the building envelope or upgraded building services. It would be expected that Premium and A grade stock would have the highest running costs as these buildings have the highest levels of specification in respect of building services. The Property Council of Australia (2008) survey of building owners reported the cost in use profiles across all grades which showed operating expenses for Premium and grade A office buildings were $\$ 62.11$ per square metre, Grade B $\$ 54.17$ per square metre, Grade C stock was highest at $\$ 73.35$ per square metre and no data available for D Grade and ungraded stock (Property Council of Australia 2008). It is considered that C grade stock is likely to have outdated building services which are not serviced regularly and that the buildings are likely to be less well maintained and not designed with energy efficiency as a priority (Property Council of Australia 2008). D Grade stock received the least amount of adaptive work. As with the B and C Grade the profile of adaptation type is replicated with minimal change of use adaptation, mostly alterations and extensions, followed by alterations and then minor works. With D grade stock the owner's motivation is to avoid rental returns decreasing and to maintain code compliance.

It was observed that 'site boundaries' refers to the degree of attachment in the building to other properties. In the CBD the smaller low rise buildings tend to be attached on two 
sides, with larger high rise stock more likely to be detached. Kincaid (2002), Povall \& Eley (in Markus 1979) and Isaacs (in Baird 1996) noted the degree of attachment affected the ease of and the attractiveness of adaptation. Detached buildings are easier to adapt externally as owners can get access to elevations. Internal adaptations are easier to carry out with detached or less attached buildings because owners can gain entry for materials and remove waste without disturbing or negotiating with neighbours. The result of the high loading indicates that in practice this observation was correct although the degree of attachment to other buildings is important.

\section{Component Two - land}

Component two contains identical variables to the third component in the PCA for alterations adaptations (level 2) namely; street frontage and property location and is named 'land' because the attributes are related to the land parcel. 0.49 of all 'alterations and extensions' adaptations over the period occurred to buildings of 40 metres width or less. The majority of alterations and extensions adaptations ( 0.71$)$ occurred to buildings 50 metres wide or less (see table 7). There is a preference to adapt buildings with smaller width and these properties are either more versatile and or have greater flexibility to accommodate adaptation.

\section{Table 7. Alterations and extensions adaptations by building width (in metres)}

Previous studies confirmed the importance of location in adaptation (Bryson 1997; Swallow 1997; Kincaid 2000; Ball 2002; Remøy and van der Voordt 2006). Property 
location is associated with adaptation and this study revealed that particular streets, such as Collins Street, Melbourne had much greater rates of adaptation than other streets i.e. 0.27 of all adaptations over the period. CBD location is scaled from prime (i.e. the best and most expensive) to fringe (i.e. the least expensive). The relationship between building width and building location reveals buildings in low prime (0.27), low secondary $(0.26)$ and prime $(0.25)$ locations are most likely to undergo adaptation, with those in fringe (0.09) and high secondary (0.13) locations least likely to be adapted. The percentages highlighted little variance between the top three locations for alterations and extensions adaptations. The results illustrated a two tier market operated in 'alterations and extensions' adaptations with most activity occurring in the top two locations (0.51) and a quarter of 'alterations and extensions' activity occurring in the low secondary zone.

This finding demonstrated that owners in the top two zones were willing to undertake major works to maintain the properties grading or position in the market, whilst those in low secondary were equally prepared to undertake extensive work to their stock. These owners were motivated by a desire either to retain tenants and/or maintain rental yields and capital values.

\section{Component Three - social}

The third component named 'social' contained three variables: historic listing, age and aesthetics. These variables were present in the fourth component for 'alterations' 
adaptations (see Wilkinson et al. (2010) for a detailed discussion) and reflect similarities in the components for different levels of adaptation. Historic listing and age are correlated where older buildings are more likely to become listed or to fall within a heritage overlay. Ball (2002), Bullen (2007) and Snyder (2005) all noted heritage listing affects adaptation. The most obvious impact is that restrictions are placed on owners with regards to the extent of work and the materials which must be used. Older buildings undergo more adaptation as time passes and it is not surprising to see age highly correlated with adaptation. Barras \& Clark (1996) and Baum (1991) concluded the correlation between time and obsolescence in buildings, demonstrating that as time passes adaptation of some form is essential to prevent a decline which otherwise can result in demolition.

Buildings which are more aesthetically pleasing underwent more adaptations (figure 1). Buildings ranked one (most aesthetically pleasing) accounted for 0.29 , second ranked 0.35 , third ranked 0.19 , fourth ranked 0.12 and least aesthetically pleasing (ranked five) 0.02 .

\section{Figure 1. Alterations \& extensions adaptations and aesthetics}

\section{Conclusions}

Important insights have been identified from this research which support an increased understanding into drivers of building adaptations. The analysis reveals three defined and 
interpreted factors which are linked to building adaptations namely; physical and size, land and social. The analysis of 'alterations and extensions adaptations' confirmed correlated variables related to building adaptations previously identified as being separate and distinct (Blakstad 2001; Kucik 2004; Arge 2005). This finding indicates the relationship between building adaptations and building attributes is more complex than hitherto considered. The PCA identified and confirmed that some attributes are more important than others.

- The most common type of adaptations undertaken were alterations and extensions (level 4), which is the most extensive type of adaptation;

- Physical building and size attributes are the most important building characteristics;

- Building appearance is more important in alterations and extensions adaptation than other types of adaptation;

- Aesthetically pleasing buildings undergo greater rates of adaptation;

- Building quality (Property Council of Australia Building Quality Grade) is an important attribute;

- C grade stock is least likely to be adapted and, as it has the highest operating costs per metre squared, it offers the best potential for reducing greenhouse gas emissions though sustainable adaptations;

- Buildings which are less attached to others are more likely to undergo alterations and extensions adaptation; 
- Buildings with a front frontage of 50 metres or less are more likely to undergo adaptation;

- Buildings with services cores located centrally are more likely to be suitable for adaptation;

- Buildings located in prime and low prime and low secondary locations have a one in four likelihood of being adapted;

- Buildings in the fringe location are least likely to be undergo adaptations; and

- Older stock undergoes more adaptation and is highly correlated with historic listing.

Starting with 42 building attributes, a sub-set of 12 attributes were found to be important, influencing adaptation to a high degree; some 0.73 of adaptation is explained by twelve attributes. Another major finding was that attributes previously considered influential were found to have limited influence on adaptation. Significantly this research has identified the most important adaptation attributes in building adaptation based on unbiased sources. In this respect the results of the study allows the work of Langston et al. (2007) and Remøy and van der Voordt $(2006,2007)$ to be progressed further and the development of a robust weighted decision-making tool more achievable.

\section{References}

Arge, K. (2005). "Adaptable office buildings: theory and practice." Facilities 23(3): 119127.

Austin, R. L. (1988). Adaptive Reuse. Issues and case studies in building preservation. New York, Van Nostrand Reinhold Company. 
Ball, R.M. (1999). Developers, regeneration and sustainability issues in the resueof vacant industial buildings. Building Research \& Information. 27(3): 140-148.

Ball, R. M. (2002). Re use potential and vacant industrial premises: revisiting the regeneration issue in Stoke on Trent. Journal of Property Research. 19: 93-110.

Barras, R. and P. Clark (1996). "Obsolescence and performance in the Central London office market." Journal of Property Valuation \& Investment 14(4): 63-78.

Blakstad, S. H. (2001). A Strategic Approach to Adaptability in Office Buildings. Faculty of Architecture, Planning \& Fine Arts, Norwegian University of Science \& Technology.

Doktor Inegnior 282.

Bryson, J., R. (1997). "Obsolesence and the process of creative reconstruction." Urban Studies 34(9): 1439-1459.

Douglas, J. (2006) Building adaptation. 2nd ed. London: Butterworth-Heinemann.

Department of Sustainabiilty and Environment (2008). PRISM, State Government of Victoria.

Francis, G. (2007). Introduction to SPSS for Windows. Sydney, Pearson Education Australia.

Heath, T. (2001). "Adaptive reuse of offices for residential use." Cities 18(3): 173-184.

Hinton, P., Brownlow, C., McMurray, I \& Cozens, B (2004) SPSS Explained. London: Routledge.

Kincaid, D. (2000). "Adaptability potentials for buidlings and infrastructure in sustainable cities " Facilities 18(3): 155-161.

Kincaid, D. (2002). Adapting buildings for changing uses. Guidelines for Change of Use Refurbishment, London: Spon Press.

Kucik, L., M. (2004). Restoring Life: The Adaptive Reuse of a Sanatorium. School of Architecture and Interior Design. Cincinnati, University of Cincinnati. Masters of Architecture: 93.

Lorenz, D. , Heard, B. , Hoekstra-Fokkink, L. , Orchard, J. and Valeri, S. (2008) Towards a city of Melbourne climate change adaptation strategy: A risk assessment and action plan. Melbourne, Vic: Maunsell Australia Pty Ltd.

Markus, T. A. (1979). Building Conversion and Rehabilitation. Designing for change in Building Use. London, The Butterworth Group. 
Ohemeng, F. (1996.). The application of multi-attirbute theory to building rehabilitation versus redevelopment options. COBRA, RICS.

Property Council of Australia (2007). Benchmarks Survey of Operating Costs.

Melbourne Office Buildings. Property Council of Australia: 36.

Property Council of Australia (2008). existing buidlings/ survival strategies. A toolbox for re-energising tired assets. Property Council of Australia: 67.

Remøy, H. T. and T. J. M. van der Voordt (2006). A new life: Transformation of vacant office buildings into housing. CIBW70 Changing User Demands on Buildings. Needs for lifecycle planning and management, Trondheim.

Remøy, H. T. and T. J. M. van der Voordt (2007). "A new life: conversion of vacant office buildings into housing." Facilities 25(3/4): 88-103. excellent conversion risk chart ofr change of use for office to residential - get hold of De Vrijs thesis?

RPData (2008). Melbourne Cityscope, Cityscope Publications Pty Ltd.

Swallow, P. (1997). "Managing unoccupied buildings and sites " Structural Survey 15(2): 74-79. 
Table 1: Summary of Attributes Influencing Building Adaptation

\begin{tabular}{|c|c|c|}
\hline $\begin{array}{l}\text { Building use } \\
\text { classification }\end{array}$ & $\begin{array}{l}\text { Internal layout - } \\
\text { columns }\end{array}$ & Net Lettable Area \\
\hline Street Number & $\begin{array}{l}\text { Location of vertical } \\
\text { services }\end{array}$ & $\begin{array}{l}\text { Property Council of } \\
\text { Australia quality grade }\end{array}$ \\
\hline Street Name & Existing land use & Floor plate size \\
\hline Street Address & Internal layout & $\begin{array}{l}\text { Cost in use profile - } \\
\text { gross income }\end{array}$ \\
\hline Property Suburb & Street frontage (width) & $\begin{array}{l}\text { Cost in use profile - } \\
\text { operating expenses }\end{array}$ \\
\hline Aesthetic qualities & Site area & Type of construction \\
\hline Plan shape & Description of building & $\begin{array}{l}\text { Elasticity potential - } \\
\text { lateral (flexibility) }\end{array}$ \\
\hline Site orientation & $\begin{array}{l}\text { Historic Listings detail } \\
\text { description }\end{array}$ & $\begin{array}{l}\text { Elasticity potential - } \\
\text { vertical (flexibility) }\end{array}$ \\
\hline $\begin{array}{l}\text { Purpose built for } \\
\text { current use }\end{array}$ & Historic listing & Site boundaries \\
\hline $\begin{array}{l}\text { Purpose built } \\
\text { commercial }\end{array}$ & $\begin{array}{l}\text { Hostile factors (includes } \\
\text { noise, smells, } \\
\text { contamination, proximity to } \\
\text { power station) }\end{array}$ & Site access \\
\hline $\begin{array}{l}\text { Building envelope and } \\
\text { cladding }\end{array}$ & Number of Storey's & Tenure type (ownership) \\
\hline $\begin{array}{l}\text { Building envelope and } \\
\text { cladding condition }\end{array}$ & Year Built & Proximity to transport \\
\hline Zoning & Year Refurbished & Green Star rating \\
\hline Proactive legislation & No of refurbishments & NABERS rating \\
\hline Roof overshadowed & Refurbishment type & ABGR rating \\
\hline $\begin{array}{l}\text { User demand - for lease } \\
\text { or sale }\end{array}$ & Parking & $\begin{array}{l}\text { Electricity consumption } \\
\$ / \mathrm{m} \text { sq. by PCA Grade. }\end{array}$ \\
\hline Occupants & Number of Car Bays & $\begin{array}{l}\text { Gas consumption } \$ / \mathrm{m} \\
\text { sq by PCA Grade.. }\end{array}$ \\
\hline Occupant Classification & Site Area & $\begin{array}{l}\text { Water consumption } \$ / \mathrm{m} \\
\text { sq. by PCA Grade. }\end{array}$ \\
\hline Typical Floor Area & Total Building Area & $\begin{array}{l}\text { Building classification } \\
\text { according Building Code } \\
\text { of Australia }\end{array}$ \\
\hline
\end{tabular}


Table 2 Building adaptation level and title

\begin{tabular}{|c|l|}
\hline Adaptation level & \multicolumn{1}{|c|}{ Title } \\
\hline Level 1 & Minor \\
\hline Level 2 & Alterations \\
\hline Level 3 & Change of Use \\
\hline Level 4 & Alterations and extensions \\
\hline Level 5 & Demolition \\
\hline Level 6 & New build \\
\hline
\end{tabular}


Table 3. Total Variance Explained PCA Level 4 adaptation events

\begin{tabular}{|c|c|c|c|c|c|c|c|}
\hline \multirow[b]{2}{*}{$\begin{array}{l}\text { Compo } \\
\text { nent }\end{array}$} & \multicolumn{3}{|c|}{ Initial Eigenvalues } & \multicolumn{2}{|c|}{$\begin{array}{l}\text { Extraction Sums of } \\
\text { Squared Loadings }\end{array}$} & $\begin{array}{l}\text { Extraction } \\
\text { Sums of } \\
\text { Squared } \\
\text { Loadings }\end{array}$ & $\begin{array}{l}\text { Rotation } \\
\text { Sums of } \\
\text { Squared } \\
\text { Loadings }\end{array}$ \\
\hline & Total & $\begin{array}{c}\% \text { of } \\
\text { Variance }\end{array}$ & $\begin{array}{c}\text { Cumulative } \\
\%\end{array}$ & Total & $\begin{array}{l}\% \text { of } \\
\text { Variance }\end{array}$ & Cumulative \% & Total \\
\hline 1 & 5.832 & 44.86 & 44.86 & 5.83 & 44.86 & 44.86 & 5.79 \\
\hline 2 & 2.572 & 19.78 & 64.65 & 2.57 & 19.78 & 64.65 & 2.33 \\
\hline 3 & 1.214 & 9.34 & 73.98 & 1.21 & 9.34 & 73.98 & 1.92 \\
\hline 4 & 0.858 & 6.60 & 80.58 & & & & \\
\hline 5 & 0.761 & 5.85 & 86.43 & & & & \\
\hline 6 & 0.614 & 4.72 & 91.15 & & & & \\
\hline 7 & 0.387 & 2.97 & 94.12 & & & & \\
\hline 8 & 0.290 & 2.23 & 96.36 & & & & \\
\hline 9 & 0.255 & 1.96 & 98.32 & & & & \\
\hline 10 & 0.118 & 0.91 & 99.23 & & & & \\
\hline 11 & 0.053 & 0.41 & 99.63 & & & & \\
\hline 12 & 0.042 & 0.32 & 99.95 & & & & \\
\hline 13 & 0.006 & 0.05 & 100.00 & & & & \\
\hline
\end{tabular}

Extraction Method: Principal Component Analysis. 
Table 4. Pattern Matrix for Level 4 adaptation events

\begin{tabular}{|l|c|c|c|}
\hline \multirow{2}{*}{} & \multicolumn{3}{|c|}{ Component } \\
\cline { 2 - 4 } & 1 & 2 & 3 \\
\hline Number of Storey's & 0.96 & 0.05 & 0.05 \\
PCA grade & 0.96 & -0.01 & 0.04 \\
Site boundaries & -0.82 & 0.02 & 0.12 \\
Typical Floor Area & 0.78 & 0.20 & -0.01 \\
Site access & 0.74 & -0.05 & 0.06 \\
Parking & 0.74 & -0.06 & 0.30 \\
Street frontage (metres) & 0.43 & -0.01 & 0.42 \\
Vertical services location & 0.04 & 0.86 & 0.03 \\
Property location & -0.63 & 0.70 & 0.13 \\
Historic listing & -0.18 & 0.18 & 0.82 \\
Age in 2010 & -0.48 & -0.12 & -0.63 \\
Aesthetics & 0.14 & 0.49 \\
\hline
\end{tabular}

Extraction Method: Principal Component Analysis. 
Table 5. Summary of Level 4 PCA Component Categories

\begin{tabular}{|c|c|c|}
\hline $\begin{array}{c}\text { Component } \\
\text { number }\end{array}$ & $\begin{array}{c}\text { Component } \\
\text { name }\end{array}$ & Component variables \\
\hline 1 & $\begin{array}{l}\text { Physical } \\
\text { and size }\end{array}$ & $\begin{array}{l}\text { Height (number of stories) } \\
\text { Gross Floor Area (GFA) } \\
\text { Property Council of Australia Building Quality } \\
\text { Grade } \\
\text { Site boundaries } \\
\text { Typical floor area } \\
\text { Site access }\end{array}$ \\
\hline 2 & Land & $\begin{array}{l}\text { Street frontage } \\
\text { Vertical services location } \\
\text { Property location }\end{array}$ \\
\hline 3 & Social & $\begin{array}{l}\text { Historic listing } \\
\text { Age } \\
\text { Aesthetics }\end{array}$ \\
\hline
\end{tabular}

